\title{
Digital Platform for Social Sphere. The Need and Problems of Creation in Russia
}

\author{
Odinokova T.D. Istomina N.A.
}

\author{
Ural State University of Economics, Yekaterinburg, Russia \\ Corresponding author.Email: tdo17@yandex.ru
}

\begin{abstract}
ABSTACT
At the present stage of development of digitalization of the economy, many new technologies are being introduced in many countries, Russia not being an exclusion. Many governments are considering the development and implementation of digital platforms in various areas of regulation, including the social sphere. In Russia, in accordance with the national project "Digital Economy", in the near future it is planned to launch a digital platform for social security, which will combine various types of services for the provision of social welfare.

The article presents the authors' conclusions regarding the advantages of introducing a digital marketplace for the social sphere. It also discloses the main problems that the government may encounter when developing and implementing a digital platform for the social sphere, the ones related to technological aspects, the specifics of the recipients of social assistance, and the imperfection of the regulatory framework. The measures that should be taken for the development and implementation of a digital social security platform are discussed.
\end{abstract}

Keywords: social services, social welfare, digital platform, social sphere marketplace, digital technologies

\section{INTRODUCTION}

At the present stage of development of the Russian economy, financial support for citizens is often provided on the basis of information that is too simplistic and not always verified. As a result, its recipients are not always those who really need it. Moreover, such support sometimes leads to an increase in the gap in living standards between different recipients of social security. In these conditions, the problem of targeted social assistance is really relevant. The use of a unified digital platform for the social sphere will allow assessing the standard of living of an elderly person or one in need of assistance, taking into account not only his income, but also his marital status, the availability of additional medical insurance and participation in a non-state corporate pension scheme, availability or non-availability of benefits, disability. In addition, a unified digital platform will eliminate the need for annual applications for social assistance.

A unified digital platform or digital marketplace of the social sphere will combine information about all types of social assistance, will allow for coordinated interaction of all participants in the planning and receipt of social assistance, and, as a result, will make it possible to make social services more personalized, i.e. taking into account the needs of a particular person.

It should be understood that the introduction of a digital marketplace for the social sphere will present certain difficulties caused by low information and technological literacy of the recipients of social welfare, the need to improve the security of personal data provided, to develop more effective methods of targeted assistance, as well as the convergence of various social protection systems and the cooperation of government departments and nongovernmental organizations providing social services.

\section{THE CURRENT STATE OF SCIENTIFIC RESEARCH}

\subsection{Targeted social assistance}

The need for research on targeted state social assistance to citizens is due to the modernization of the social protection system, the need to strengthen the fight against poverty, and the reform of the work of social institutions. The targeted approach is implemented in all models of social policy in a varying degree, even despite the criticism by the proponents of the principle of universality of social assistance (benefits to everyone) [1, p. 78]. In modern Russia, targeted assistance in the social protection system is a priority, since in the conditions of economic instability there is need for a budgetary restriction policy, the number of people below the poverty line has increased, which forces the state to implement a more rational social protection policy and identify those citizens who need it first. 
Issues of targeted assistance as a component of the social protection system are considered in a rather extensive list of scientific papers. Firstly, these include works on the establishment and development of a social protection system for various categories of the population as a way to cope with poverty $[1,2,3,4]$. Secondly, there is a significant number of works dedicated to the process of forming a system of targeted social assistance [5,6,7,8,9]. Thirdly, there are studies that reveal the specifics of targeted assistance in the field of pension insurance and security $[10,11,12,13]$, studies of criteria for assessing the cost of living of pensioners are of particular importance for understanding security provision. It is also necessary to note the studies devoted to assessing the effectiveness of the introduction of digital technologies in the social sphere $[14,15]$.

However, despite the abundance of scientific work, the topic of the specifics of using a digital platform for the social sphere remains poorly understood. The platform, which will make it possible to really assess the standard of living of an elderly or needing help person and take into account not only their real income, but also additional sources of improving the quality of life, is needed. Therefore, the problem of developing targeted social assistance to the population at the current stage has become relevant both in practical and theoretical terms. In conceptual terms, targeted social assistance, like the entire system of social protection of the population, does not have a clear effective model. Currently, models designed to provide a minimum income guarantee are mainly used. In Russia, the minimum income is defined as the cost of living, a criterion for the level of poverty, which provides for not only biological, but also social survival of a person. Common to all countries are the principles of establishing the cost of living as defined by the Convention of the International Labor Organization [8. P.105-106]: "When establishing the minimum cost of living, such basic needs of working families as food and their calorie content, housing, clothing, medical care and education are taken into account" [16].

In Russia, in the coming years, it is planned to implement 10 social programs totaling $4,184.4$ billion rubles. Two of the programs planned on the beginning of 2020 have not been developed yet. They are the development of a pension system and the social support system for citizens. However, a number of measures for these two programs are already operating under separate federal or regional laws, which include conditional cash transfers, housing benefits, food programs, social pensions, child benefits, disability allowance, social benefits for pensioners.

\subsection{Digital platform for the social sphere}

The digital platform aims to create a human-centered social environment. Digital platforms are considered as evolving systems (such as Facebook or Twitter), consisting of a set of stabilized core elements and new functions generated by mutual interaction of their users and developer communities (18, 19 Spagnoletti).

There is no unified digital platform for the social sphere in Russia yet, it is under development. The developers of the digital marketplace for social security are faced with the task of uniting departments, citizens, as well as nongovernmental organizations providing social services to the population. Today, only at the federal level there are many state information systems (GIS) requiring integration, among them the automated information system (AIS) "Registers of the Recipients of Services", AIS PFR, the Federal Register of Disabled People, a unified integrated information system "Social Insurance", SIS of compulsory medical insurance, etc. Partially, the role of integration of departmental systems is assigned to the unified SIS of social security, but it does not allow combining the work of various organizations and citizens, that is it cannot be a digital platform. At the regional level, each subject itself determines the type of software product that it will use when working with the social welfare department. For example, the AIS "Targeted Social Assistance" is used in 60 of 83 constituent entities of the Federation.

\subsection{Pension benefits in terms of personalized social services}

Existing mechanisms for retirement on a voluntary basis, the ability to receive a pension and continue to work, the absence of age restrictions in labor legislation together define the state employment policy as age and pension status of employees neutral. Providing minimum income insurance to all citizens who have reached retirement age, the state does not establish any special employment regimes for them. According to this logic, all those who are able to adapt to labour market demands, do it, and the incapable ones become social security recipients [4. P. 12], who rely on payments of various nature: pension benefit, funds for state support, additional social payments in cash and in kind.

The pension coverage of each recipient is determined individually, the amount of it depends on the influence of various circumstances. First of all, it depends on the length of service (insurance), mandatory contributions to the funded and insurance pension, additional insurance contributions under the state co-financing program of pensions and other additional contributions. Secondly, it depends on various regional payments and on participation in voluntary corporate and / or individual pension insurance programs.

The Pension Fund of the Russian Federation (PFR) opens 
an individual personal account, which takes into account all the rights of the insured person, for each person in the system of obligatory pension insurance (OPI). The existence of an information database for individual (personified) accounting of pension rights of citizens allows the PFR to carry out an unauthorized adjustment of some data when indexing, valorizing, converting and recalculating state pensions [17].

The main criteria for providing social assistance to older people are: appropriate age; social status; insufficient income for a normal life (for example, for the purchase of medicines, payment of utility bills, taxes, the acquisition of necessary products). Thus, the category of persons who are granted social protection includes: elderly people who retired after military service; former employees of the Ministry of the Interior; citizens for whom pension is the only income; single pensioners; people over 70 years old; a married couple of pensioners, one of whom is already 70 years old.

\section{RESULTS}

The introduction of a unified digital marketplace for the social sphere will provide such benefits as:

- raising public awareness in the provision of social protection;

- biometric authentication, identification and assessment of the standard of living of an elderly or needing person. Not only his income, but also his marital status, the availability of additional medical insurance and participation in a non-state corporate pension scheme, availability or nonavailability of benefits, disability are considered;

- reduction in the document flow and the processing time of information received by government departments and non-governmental organizations from the recipients of social welfare;

- tracking payments at the second level, in the state system itself;

- involvement of non-governmental organizations and citizens themselves in the process of ensuring social protection.

When developing and implementing a digital platform for the social sphere, the state may face a number of problems:

- information and technological illiteracy of recipients of targeted social assistance;

- technical accessibility to the necessary infrastructure (for example, to a computer), lack of competence in how to use the tools of social networks, and understanding of the potential impact on their social and medical situation [20].

- the lack of a single, holistic understanding of the concept of targeted social assistance in the context of the creation and operation of a digital platform;
- increased costs for developers to ensure the protection of personal data of the recipients of social assistance;

- the lack of a regulatory framework for regulating relationships through various digital services, including the marketplace;

- the presence of certain technological difficulties in terms of convergence of various social protection systems and the cooperation of government departments and non-governmental organizations providing social services;

- the need to develop more effective methods of targeted social assistance;

- the growth of requirements for the social protection system.

A number of measures should be taken to develop and implement a digital social security platform. First, the creation of conditions for the development of Internet technologies (for example, social networks) to support older people [14]. Digital networks for older people support can add value and remove barriers related to the digital gap by providing access to information, counseling and improving collaboration and information exchange between all people concerned on both sides of the network (i.e., private and professional) (20, 21 ) Secondly, deeper detailed analysis of the main trade-offs and the advantages and disadvantages of "precise targeting" for poverty reduction is needed. The impact of digitalization on tradeoffs needs to be carefully studied with due regard to the institutions and social norms that structure society [9]. Thirdly, it is necessary to create the necessary technical assistance and legal framework in providing access to the digital platform and its functioning for all participants of social security sphere.

\section{DISCUSSION OF RESULTS}

Given the said above, a number of measures should be taken to implement a unified digital social security platform in Russia. Firstly, it is important to introduce digital solutions quickly, directionally and comprehensively, ensuring maximum economic, social and managerial effectiveness. Secondly, to intensify efforts to popularize and support decision-making of nonstate enterprises providing social services, to integrate their systems into a digital social security platform. Thirdly, to introduce tax and non-tax preferences for nonstate enterprises providing social services, since the integration of systems is expensive. Besides, to intensify the process of biometric data collecting of all the recipients of social services. In addition, to take maximum information security measures to protect recipients' personal data from dishonest users, since in the near future as a result of the development of digital technologies, the risk of manipulation or misuse of other people's data will be one of the most significant risks not only in Russia, but also abroad. To this, to accelerate the development and adoption of regulatory acts aimed at regulating digital 
[4] Kozina, I. M., Zangiev, I. K. (2018). State and market regulation of labor activity of pensioners. The Journal of Social Policy Studies, 16 (1), 7-22. DOI: https://doi.org/10.17323/727-0634-2018-16-1-7-22

[5] Tikhomirova V.V., Targeted social assistance in the social protection system. Syktyvkar: Komi Scientific Center, Ural Branch of the Russian Academy of Sciences, 2013.138 p.

[6] Erdem Yörük, İbrahim Öker, Lara Şarlak, Indigenous unrest and the contentious politics of social assistance in Mexico, World Development, Volume 123, 2019, 104618, ISSN 0305-750X, DOI: https://doi.org/10.1016 /j.worlddev.2019.104618 (http://www.sciencedirect.com/science/article/pii/S0305 750X19302128)

[7] Gutsko P.A., State targeted social assistance in the Republic of Belarus // In the collection: Management of socio-economic systems and legal research: theory, methodology and practice Materials of the international scientific and practical conference. 2017.S. 89-98

[8] Tikhomirova V.V., Investments in targeted social assistance programs // Bulletin of the Komi Republican Academy of Public Administration and Management. Series: Theory and Practice of Management. 2014. No. 12 (17). S. 105-112.

[9] Chapter 9. The Digital Revolution and Targeting Public Expenditure for Poverty Reduction. In Digital Revolutions in Public Finance. USA: Internacional Monetary Fund.

DOI: https://doi.org/10.5089/9781484315224.071

[10] Ralston M., Schatz E., Menken J., Xavier GómezOlivé F. \& Tollman S. (2019) Policy Shift: South Africa's Old Age Pensions' Influence on Perceived Quality of Life, Journal of Aging \& Social Policy, 31: 2, 138-154, DOI: 10.1080 / 08959420.2018.1542243

[11] Birmingham, B. Occupational pensions and social assistance. Pensions Int J 6, 336-354 (2001). DOI: https://doi.org/10.1057/palgrave.pm.5940174

[12] Kohl J. (1993) Minimum Standards in Old Age Security and the Problem of Poverty in Old Age. In: Atkinson A.B., Rein M. (eds) Age, Work and Social Security. Palgrave Macmillan, London DOI: https://doi.org/10.1007/978-1-349-22668-9_9

[13] Goedemé T. (2013) Minimum Income Protection for Europe's Elderly: What and How Much has been Guaranteed during the 2000s ?. In: Marx I., Nelson K. (eds) Minimum Income Protection in Flux. Reconciling Work and Welfare in Europe. Palgrave Macmillan, London DOI: https://doi.org/10.1057/9781137291844_5 
[14] P. Spagnoletti, A. Resca, Ø.S. Bø, Design for social media engagement: Insights from elderly care assistance, The Journal of Strategic Information Systems, Volume 24, Issue 2, 2015, Pages 128-145, ISSN 0963- 8687, https://doi.org/10.1016/j.jsis.2015.04.002.

(http://www.sciencedirect.com/science/article/pii/S0963 868715000232)

[15] Tixier M. et al. (2010) Practices Analysis and Digital Platform Design: An Interdisciplinary Study of Social Support. In: Lewkowicz M., Hassanaly P., Wulf V., Rohde M. (eds) Proceedings of COOP 2010. Springer, London DOI: https://doi.org/10.1007/978-184996-211-7_17

[16] ILO Convention No. 117 (Article 5, Part 2), ILO Convention No. 82 (Article 9, Part 2) // Conventions and Recommendations adopted by the International Labor Conference. 1957-1990. - Geneva: International Labor Office, 1991. - T.II. - S.1321-1329

[17] Odinokova T.D., PFR expenses optimization tools for insurance pension payments // Insurance business. 2016.S. 15-23

[18] O. Hanseth, K. Lyytinen, Design theory for dynamic complexity in information infrastructures: the case of building internet, Journal of Information Technology, 25 (1) (2010), pp. 1-19

[19] P. Spagnoletti, A. Resca, G. Lee, A design theory for digital platforms supporting online communities: a multiple case study, Journal of Information Technology (2015), 10.1057 / jit.2014.37

[20] Godfrey, O. Johnson, Digital circles of support: meeting the information needs of older people, Computers in Human Behavior, 25 (3) (2009), pp. 633642

[21] F. Griffiths, J. Cave, F. Boardman, J. Ren, T. Pawlikowska, R. Ball, et al. Social networks - the future for health care delivery, Social Science \& Medicine, 44 (2012), pp. 1-9 